\title{
Development of a Visible Spectrophotometric Method for the Analysis of Ganciclovir in Bulk Sample and Dosage Form
}

\author{
Olusegun E Thomas and Olajire A Adegoke* \\ Department of Pharmaceutical Chemistry, Faculty of Pharmacy, University of Ibadan, Ibadan, Nigeria \\ *For correspondence: Email: jireade@yahoo.com; ao.adegoke@mail.ui.edu.ng; Tel: +234 8036381625

\begin{abstract}
Purpose: To develop and validate a simple visible spectrophotometric method for the quantitative determination of ganciclovir in bulk sample and dosage form.

Method: The method was based on the diazo coupling reaction between diazotized ganciclovir and acidified p-dimethylaminobenzaldehyde. Various analytical parameters for the azo adduct were established. Validation of the new method was carried out using current ICH guidelines with parameters including linearity, repeatability, reproducibility and selectivity determined. The developed method was thereafter applied to determine ganciclovir in a commonly available brand.

Results: Coupling reaction generated a yellow-coloured product in an alcohol medium with optimal wavelength at $404 \mathrm{~nm}$. Linear correlation was obtained at concentrations of $10.3-25.7 \mu \mathrm{g} / \mathrm{mL}$. The method was accurate and precise with recovery in the range of $99.37-103.15 \%$ while intra- and interday precision (\% RSD) at three different concentrations was $<2.7 \%$. The limits of detection and quantification were 0.23 and $0.70 \mu \mathrm{g} / \mathrm{mL}$, respectively. When applied to the analysis of the dosage form, there was no statistically significant difference between the new method and the official HPLC method. Conclusion: The method is simple, inexpensive, reproducible and fast, and can be employed as a reliable alternative to the official method for the routine analysis of ganciclovir in bulk and dosage forms.
\end{abstract}

Keywords: Ganciclovir, p-dimethylaminobenzaldehyde, Diazo coupling reaction, Absorption spectrophotometry

Tropical Journal of Pharmaceutical Research is indexed by Science Citation Index (SciSearch), Scopus, International Pharmaceutical Abstract, Chemical Abstracts, Embase, Index Copernicus, EBSCO, African Index Medicus, JournalSeek, Journal Citation Reports/Science Edition, Directory of Open Access Journals (DOAJ), African Journal Online, Bioline International, Open-J-Gate and Pharmacy Abstracts

\section{INTRODUCTION}

Ganciclovir was the first effective drug licensed for use in the prophylaxis of cytomegalovirus infections which remains the most frequently reported viral complication in patients receiving solid organ transplant $[1,2]$.

Ganciclovir, a nucleoside analogue, is chemically known as 9-(1, 3-Dihydroxy-2-propoxymethyl) guanine and has a molecular weight of 255.2 $\mathrm{g} / \mathrm{mol}$. Ganciclovir is equally active against
Herpes simplex virus 1 and 2, Epstein-Barr virus, varicella zoster virus and Herpes 6, 7 and 8 . Its mode of action involves its selective accumulation in infected cells, intracellular conversion to triphosphate by the viral enzymes (deoxyguanosine kinase, guanylate kinase, phosphoglycerate kinase) and the subsequent incorporation of the active triphosphate into viral DNA. This leads to the inhibition of viral DNA synthesis following the inhibition of DNA polymerase enzyme [3,4]. 
Literature review shows that a number of HPLC methods have been developed for the analysis of ganciclovir in biological sample matrices $[5,6]$. Although liquid chromatography with UV, fluorescence, mass spectrometry or electrochemical detection remains the most frequently used method, analysis by HPLC is often difficult because of the extensive retention of ganciclovir on non-polar stationary phases like C-18 reversed phase columns [7].

A number of alternative methods of analysis have been developed for the quantification of ganciclovir in bulk and dosage forms. These include spectrophotometric determination [8], voltammetry [9], reversed phase HPLC [10] and titrimetric quantification of unreacted oxidant following the oxidation of ganciclovir with cerium (IV) sulphate in acidic medium [11]. In the oxidimetric study, an alternative method of quantifying the unreacted oxidants following its reaction with $\mathrm{p}$-dimethylaminobenzaldehyde to form a brown adduct with $\lambda_{\max }$ of $460 \mathrm{~nm}$ was also described. Some visible spectrophotometric methods have been developed for the analysis of ganciclovir and include; the formation of different coloured products following the oxidation of ganciclovir with several inorganic oxidants [12] or charge-transfer complexation [13], reaction of ganciclovir with quinalizarin reagent [14], oxidation with 1-fluoro-2, 4-dinitrobenzene or $\mathrm{N}$ Bromosuccinimide reagents [15].

Although the HPLC and immunoassay techniques described above remain the most frequently employed assay technique, they require sophisticated equipment that is not readily available in developing countries for routine analysis. Similarly, nearly all of the other described methods require drastic reaction conditions like use of buffer solutions, high concentration of mineral acids and extensive extraction procedures.

In this present work, a simple visible spectrophotometric quantification of ganciclovir in bulk and dosage form is proposed and described. It is based on the formation of a yellow azo adduct following the coupling reaction between diazotized ganciclovir and $p$ dimethylaminobenzaldehyde (DMAB). To the best of our knowledge, this represents the first reported method based on the utilization of diazotized ganciclovir as analyte. The successful use of DMAB as a coupling reagent in the analytical determination of acyclovir [16] and many analytes of varied functionalities have been previously documented [17]. The new method is envisaged to provide an alternative approach to the quantitative estimation of ganciclovir.

\section{EXPERIMENTAL}

\section{Equipment}

Lambda 25 with UV WinLab V2.85 software (Perkin Elmer USA), analytical balance (Ohaus Pioneer, Canada), thermostated water bath (Surgifriend, England) and vortex mixer (GriffinsGeorge, UK) were utilized in this study.

\section{Materials and reagents}

All solvents, salts and acids used in this study are of analytical grade including sodium nitrite, hydrochloric acid, sulphuric acid and sulphamic acid (BDH, UK), methanol (Sigma-Aldrich, Germany), DMAB (Aldrich, UK), sulphamic acid (Kemlight, India), Ganciclovir chemical reference, Ganguard $₫ 500$ mg (Ganciclovir sodium powder for injection Ranbaxy, India was purchased from a retail outlet in Lagos, Nigeria). Distilled water was used for all preparations and dilutions. A $0.03 \%$ DMAB in $0.0625 \mathrm{M}$ sulphuric acid solution was prepared. $0.1 \mathrm{M}$ sodium nitrite and $0.2 \mathrm{M}$ sulphamic acid solutions were also prepared.

\section{Preparation of standard solutions}

An accurately weighed amount $(0.257 \mathrm{~g})$ of pure reference ganciclovir was transferred into a 50 $\mathrm{mL}$ volumetric flask, and dissolved in a small quantity of $0.1 \mathrm{M} \mathrm{HCl}$. The resulting solution was then made up to volume with $0.1 \mathrm{M} \mathrm{HCl}$ to form the standard stock solution. A $514 \mu \mathrm{g} / \mathrm{mL}$ working solution was prepared by diluting $1 \mathrm{~mL}$ of the stock solution to $10 \mathrm{~mL}$ final volume with $0.1 \mathrm{M} \mathrm{HCl}$ in a volumetric flask.

\section{Analytical procedure}

A $5 \mathrm{~mL}$ portion of ice-cold solution of ganciclovir was transferred into a $25 \mathrm{~mL}$ beaker. $1.5 \mathrm{~mL}$ of ice-cold $0.1 \mathrm{M}$ sodium nitrite was added and the mixture stirred in an ice bath continuously for 10 min. Thereafter, $0.2 \mathrm{~mL}$ of $0.2 \mathrm{M}$ sulphamic acid was added to neutralize excess nitrous acid while the solution was continuously stirred until no more frothing was observed. Freshly prepared diazotized solution was used for the following experimental procedures.

\section{Evidence of coupling reaction}

The ability of DMAB to form azo adduct with diazotized ganciclovir was investigated as previously reported for acyclovir [16]. Evidence 
for the reaction was established by spot test and thin layer chromatography (TLC). Reversed phase TLC was carried out using methanol: water (4:6) and normal phase mobile phases were ethyl acetate: methanol (9:1) and ethyl acetate: methanol (8:2). The formation of new adduct or otherwise was determined by inspection of developed plates under the UV lamp.

\section{Optimization of reaction conditions}

The analytical wavelength was selected by the inspection of the overlaid absorption spectra of the drug, diazotized drug and the product of the coupling reaction between the diazotized drug and DMAB. The diazotization time and concentration of reagents employed were optimized for the development of maximum colour intensity. The optimization of the coupling temperature and time was carried out by the method of steepest ascent [18]. This was carried out at temperatures of $30,50,60,70$ and $80{ }^{\circ} \mathrm{C}$ after incubation times of 5 and $10 \mathrm{~min}$ at each temperature level. The optimum time required for coupling at the selected temperature, $60{ }^{\circ} \mathrm{C}$ was determined by carrying out reactions at $0,2,5$, $10,15,20,25$ and $30 \mathrm{~min}$.

\section{Stoichiometric determination using the Job's method of continuous variation [19]}

For this determination, increasing volumes between 0 and $1.0 \mathrm{~mL}$ of the diazotized ganciclovir was made up to $1 \mathrm{~mL}$ with appropriate amounts of DMAB solution. The reaction mixture was vortex mixed for $10 \mathrm{~s}$ and maintained at $60{ }^{\circ} \mathrm{C}$ for $10 \mathrm{~min}$. The reaction was then stopped by cooling in ice and the volume of the solution made up to $5 \mathrm{~mL}$ with methanol. The absorbance readings were taken at $404 \mathrm{~nm}$ with methanol as the blank solvent. All determinations were carried out in duplicate.

\section{Validation of the new method of analysis}

The calibration line was generated from the 3day average of curves using $0,0.1,0.12,0.15$, 0.2 and $0.25 \mathrm{~mL}$ (equivalent to $0,10.26,12.31$, $15.39,20.52$ and $25.65 \mu \mathrm{g} / \mathrm{mL}$ ) of the diazotized drug. $0.5 \mathrm{~mL}$ DMAB solution was added to each test tube, vortex mixed for $10 \mathrm{sec}$ and the mixture maintained at $60{ }^{\circ} \mathrm{C}$ for $10 \mathrm{~min}$. Thereafter, the reaction was stopped with cooling in ice and each reaction mixture was made up to $5 \mathrm{~mL}$ with the required volume of methanol. The absorbance reading was taken at $404 \mathrm{~nm}$ with methanol as blank. Each determination was carried out in triplicate.
The suitability of the proposed method for the assay of ganciclovir was examined by determining the model recoveries and repeatability of the method on three successive days as stipulated by the $\mathrm{ICH}$ [20]. The intra- and inter-day accuracies and precisions of the proposed method were assessed from the results of replicate analyses on the pure drug solutions. The mean values and relative standard deviations for replicate analyses at three different concentration levels were calculated. The limit of detection (LOD) and limit of quantification (LOQ) were calculated as $3.3 \mathrm{\sigma} / \mathrm{S}$ and $10 \mathrm{\sigma} / \mathrm{S}$ respectively where, $\sigma$ is the standard deviation of the absorbance of blank $(n=6)$ and $S$ is the slope of the calibration line [20].

\section{Method selectivity}

The selectivity of the new method was examined by determining the recovery of the diazotized drug $(17.4 \mu \mathrm{g} / \mathrm{mL})$ in sample matrices containing the commonly used pharmaceutical aids; starch, lactose, magnesium stearate, talc and gelatin.

\section{Assay of dosage form}

An accurately weighed amount of the powder for injection equivalent to $0.513 \mathrm{~g}$ ganciclovir was transferred to a $100 \mathrm{~mL}$ standard flask and dissolved in a small quantity of $0.1 \mathrm{M} \mathrm{HCl}$. The solution was then made up to volume with $0.1 \mathrm{M}$ $\mathrm{HCl}$. A final working solution was prepared by diluting $1 \mathrm{~mL}$ of the stock solution to $10 \mathrm{~mL}$ with $0.1 \mathrm{M} \mathrm{HCl}$. The resulting solution of the analyte was subsequently used for diazotization as described in the procedure above.

A $0.17 \mathrm{~mL}$ aliquot of the diazotized solution (equivalent to $17.4 \mu \mathrm{g} / \mathrm{mL}$ ganciclovir) was mixed with $0.5 \mathrm{~mL}$ of $0.03 \%$ DMAB solution using a vortex mixer for $10 \mathrm{~s}$. The reaction was maintained at $60{ }^{\circ} \mathrm{C}$ for $10 \mathrm{~min}$ and thereafter stopped by cooling in ice and then made up to 5 $\mathrm{mL}$ with methanol. The absorbance reading was taken at $404 \mathrm{~nm}$.

The official HPLC method of assay of ganciclovir was also carried out on the dosage form [21]. Six replicate determinations using both methods were done.

\section{RESULTS}

\section{Evidence of coupling reaction}

The formation of a new product following coupling was established with spot test and TLC analysis of the reaction mixture. The diazotized ganciclovir gave an instant yellow adduct with 
DMAB. This new colour was quite distinct from the colorless solutions of ganciclovir, its diazonium salt or DMAB. Similar results were observed after incubation at elevated temperature $\left(70{ }^{\circ} \mathrm{C}\right)$ and prolonged time $(20$ min). The intensity of the yellow product was stable for more than $4 \mathrm{~h}$ when monitored by its absorbance. Normal-phase and reversed-phase TLC analysis of the adduct in three different mobile phases showed the formation of a single product with retardation factor, Rf values distinct from those of the diazotized ganciclovir and DMAB.

\section{Selection of analytical wavelength}

The overlaid spectra of ganciclovir, its diazotized derivative and the azo adduct formed between diazotized ganciclovir and DMAB are presented in Figure 1.

\section{Optimization of reaction variables}

\section{Development of colour intensity}

The concentration of the acids used in preparation of DMAB and ganciclovir stock solutions was found to be critical in the coupling reaction for the formation of optimal colour intensity. Similarly, the amount and concentration of sulphamic acid used in the removal of excess nitrous acid at the completion of diazotization was also critical as an excess or a complete change to urea led to reduction in colour intensity. Thus, the optimal acid concentration was found to be $0.0625 \mathrm{M}$ while the amount of sulphamic acid used for stopping the diazotization reaction was kept at optimum value of $0.2 \mathrm{ml}$ of $0.2 \mathrm{M}$ solution all the time.

\section{Selection of coupling temperature and time}

The optimal reaction temperature and heating time were established at $60{ }^{\circ} \mathrm{C}$ and $10 \mathrm{~min}$ respectively. Heating temperatures or time led to decrease in the absorbance which is probably due to the thermal decomposition of the coupling product.

\section{Stoichiometric ratio and reaction mechanism}

The highest absorbance values were obtained at $1: 1$ ratio indicating only the presence of one diazotizable group in ganciclovir. With this result and coupled with observation of the presence of a single spot in the TLC analysis of the reaction mixture, a 1:1 azo adduct formation is proposed as the underlying basis for the reaction mechanism.

\section{Validation of the new method}

\section{Linearity and calibration line}

A linear correlation was obtained at wavelength of $404 \mathrm{~nm}$ and at concentrations of 10.3-25.7 $\mu \mathrm{g} / \mathrm{mL}$ of ganciclovir.

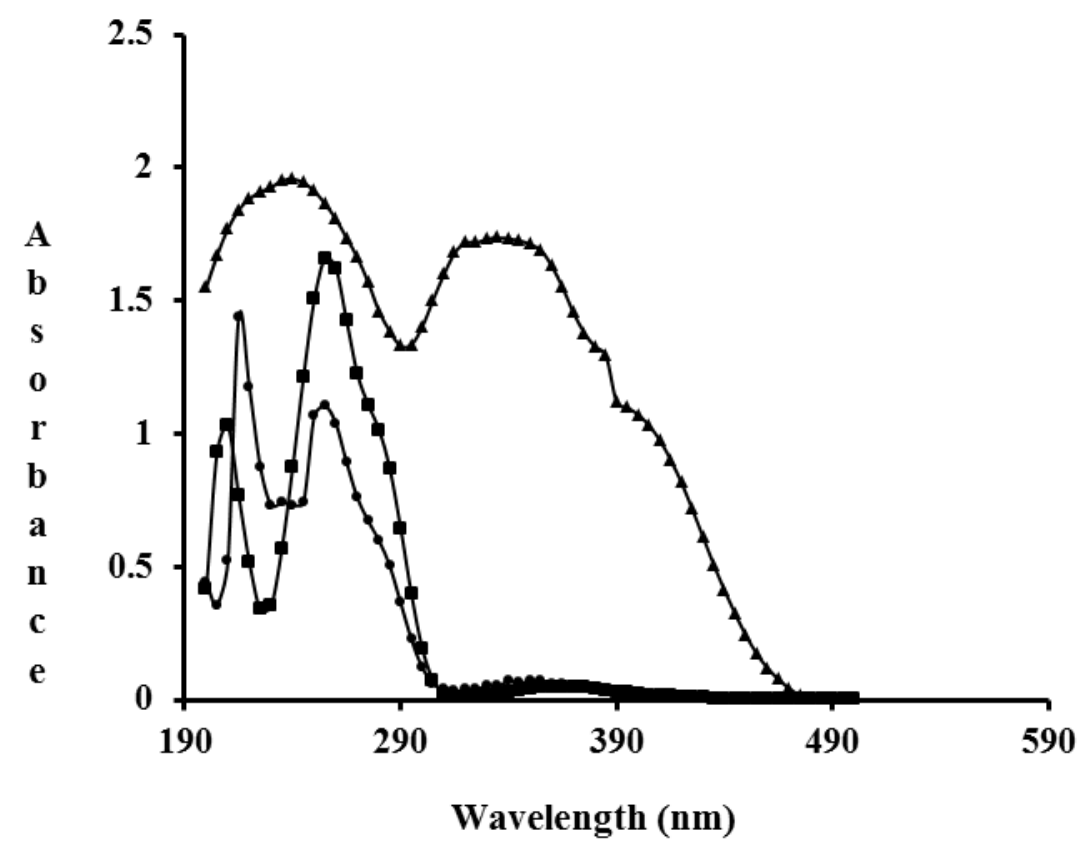

Figure 1: Overlaid spectra of ganciclovir ( $\mathbf{\square})$, diazotized ganciclovir $(\diamond)$ and adduct $(\boldsymbol{\Delta})$ 
The correlation coefficient was very close to unity. The $95 \%$ confidence limits for the slope and the intercept depicted the suitability of the method for the proposed analytical utility. Likewise, the lowest limits of detection and quantitation compared favorably with previously reported methods for ganciclovir. The various analytical parameters are presented in Table 1.

Table 1: Analytical and validation parameters for the new method

\begin{tabular}{lc}
\hline Performance parameter & Value \\
\hline Beer's Law Limit $(\mu \mathrm{g} / \mathrm{mL})$ & $10.3-25.7$ \\
Limit of detection $(\mu \mathrm{g} / \mathrm{mL})$ & 0.23 \\
Limit of quantification $(\mu \mathrm{g} / \mathrm{mL})$ & 0.70 \\
Molar absorptivity $\left(\mathrm{L} \mathrm{mol}{ }^{-1} \mathrm{~cm}^{-1}\right)$ & $8.7 \times 10^{3}$ \\
Sandell's sensitivity $\left(\mu \mathrm{g} \mathrm{cm} \mathrm{cm}^{-2}\right.$ per & 0.033 \\
$0.001 \mathrm{~A})$ & \\
Slope $\pm \mathrm{SD}$ & $0.0304 \pm 2.52 \times 10^{-4}$ \\
Intercept $\pm \mathrm{SD}$ & $0.0399 \pm 0.011$ \\
Correlation coefficient & 0.999 \\
Coefficient of determination & 0.998 \\
\hline
\end{tabular}

Assessment of accuracy and precision of the proposed method for ganciclovir

The results for the intra- and inter-day accuracy and precision of the new spectrophotometric method are presented in Table 2. The results show the new method having a percentage recovery of 98.4-103.2 \% and percentage relative error of $3.14 \%$. This projects the new method as accurate since the relative error is less than $5 \%$. The method also showed good repeatability as the percentage RSD did not exceed $2.4 \%$.

For the inter-day results, the percentage recovery and percentage relative error of the new method were 98.9-102.6 \% and $2.6 \%$ respectively indicating high accuracy. Similarly, the percentage relative standard deviation did not exceed $3.1 \%$ indicating good reproducibility.

\section{Interference studies}

The recovery of ganciclovir in the presence of the excipients was between $95.3 \%$ and $102.9 \%$ indicating good selectivity of the method and hence depicting lack of interference by commonly used excipients in dosage forms.

Assay of dosage form and comparison of performance with official method

The new method was applied to the content analysis of the available ganciclovir injectable preparation. The results obtained as well as the comparison of the performance parameters of the new and official methods are presented in Table 3. With both methods, the label claims of the active content were within the specified limits of $90-110 \%$.

\section{DISCUSSION}

The reaction of diazotized ganciclovir with DMAB gave an instant yellow-colored solution. The formation of the color depicts the presence of new chemical species which was proven through the TLC analysis of the reaction mixture.

On investigating the spectral patterns (Figure 1) of the various species involved in this new method, ganciclovir has well-defined absorption peaks at 215 and $250 \mathrm{~nm}$ while DMAB has prominent peaks at 215, 250, 300 and $350 \mathrm{~nm}$. On diazotizing ganciclovir, the absorption peak at $215 \mathrm{~nm}$ was maintained with a slight bathochromic shift of the $250 \mathrm{~nm}$ peak $(\Delta \lambda=+5$ $\mathrm{nm}$ ) to $255 \mathrm{~nm}$.

Table 2: Accuracy and precision of new method

\begin{tabular}{|c|c|c|c|c|c|c|}
\hline \multirow{2}{*}{$\begin{array}{l}\text { Amount } \\
\text { added } \\
\text { ( } \mu \mathrm{g} / \mathrm{ml})\end{array}$} & \multicolumn{3}{|c|}{ Intra-day* } & \multicolumn{3}{|c|}{ Inter-day** } \\
\hline & $\begin{array}{c}\text { Mean recovery } \\
(\%)\end{array}$ & $\begin{array}{l}\text { RSD } \\
(\%)\end{array}$ & $\begin{array}{l}\text { Relative error } \\
(\%)\end{array}$ & $\begin{array}{l}\text { Mean recovery } \\
(\%)\end{array}$ & $\begin{array}{l}\text { RSD } \\
(\%)\end{array}$ & $\begin{array}{l}\text { Relative } \\
\text { error (\%) }\end{array}$ \\
\hline 12.31 & $99.37 \pm 0.16$ & 1.34 & 0.63 & $99.79 \pm 0.38$ & 3.11 & 0.21 \\
\hline 17.44 & $103.15 \pm 0.4$ & 2.37 & 3.14 & $102.64 \pm 0.40$ & 2.11 & 2.63 \\
\hline 23.60 & $98.36 \pm 0.44$ & 1.85 & 1.64 & $98.91 \pm 0.56$ & 2.38 & 1.09 \\
\hline
\end{tabular}

${ }^{*} n=4$ for each concentration level, ${ }^{* *} n=12$ for each concentration (average of three days)

Table 3: Comparative analytical data for dosage form of drug based on the proposed and official HPLC methods

\begin{tabular}{|c|c|c|c|c|c|c|c|}
\hline \multirow[b]{2}{*}{$\begin{array}{l}\text { Drug formulation ( } 0.5 \mathrm{~g} \\
\text { strength) }\end{array}$} & \multicolumn{2}{|c|}{ New method } & \multicolumn{2}{|c|}{ HPLC method } & \multicolumn{3}{|c|}{ Statistical data } \\
\hline & $\begin{array}{l}\text { Amount } \\
\text { found (g) }\end{array}$ & $\begin{array}{l}\text { RSD } \\
(\%)\end{array}$ & $\begin{array}{l}\text { Amount } \\
\text { found (g) }\end{array}$ & $\begin{array}{l}\text { RSD } \\
(\%)\end{array}$ & $\begin{array}{c}\text { Mean recovery } \\
(\%)^{*}\end{array}$ & F-test & t-test \\
\hline Ganguard $^{(\circledast)}$ & 0.53 & 3.78 & 0.55 & 4.98 & 96.4 & 0.54 & 0.16 \\
\hline
\end{tabular}

*ratio of the results obtained with the new method to that of the official method 
However, following the coupling reaction of diazotized ganciclovir with DMAB, a completely different UV absorption spectrum was obtained. There was a marked bathochromic and hyperchromic shifts of the spectrum of the new adduct relative to the diazotized ganciclovir and DMAB with prominent peaks at 235 and $335 \mathrm{~nm}$ and a shoulder at $400 \mathrm{~nm}$. Optimal difference in absorptivity was observed when absorbance measurements were recorded at $404 \mathrm{~nm}$. This wavelength $(404 \mathrm{~nm}$ ) was therefore selected as analytical wavelength as it showed little or no background absorptivity from interfering components in the sample matrix.

The proposed method is based on the coupling reaction between the generated diazonium ion which was reactive towards activated ring systems such as p-DMAB. Optimal reaction was facilitated at an elevated temperature. Elevated temperature has been found to be useful for the utilization of DMAB in coupling reaction since the diazonium ion generated from the drug was not intensely reactive compared to conventional benzene diazonium ions.

The coupling reagent consists of an aromatic system sandwiched between an electron donor and acceptor. The electronic effect of DMAB was therefore significantly improved by the contributions of its two canonical structures (the neutral benzenoid structure and the zwitterionic quinonoid structure with negative and positive charges on the oxygen and nitrogen respectively) in the electronic ground state. In addition, a combined influence of the activating orthodirecting tertiary amino group and the meta- directing aldehyde group made the 3- and 5positions on the DMAB moiety available to an incoming electrophile. The successful use of $D M A B$ as coupling agent for diazotizable groups including primary amino groups and reducible nitro groups present on aromatic skeletons have been demonstrated $[16,22]$. As previously reported, the utilization of alcoholic solution (particularly methanol) repressed the deactivating influence of aldehyde group while the activating potential of the dimethylamino group was optimal. This led to ready substitution of the incoming electrophile and hence formation of a yellow-colored solution. The proposed coupling reaction pattern of the new method is depicted in Figure 2.

Following the optimization studies for the formation of the new azo adduct between DMAB and diazotized ganciclovir, a comparative study of the suitability of the new method to assay the drug in a dosage form was carried out alongside the official HPLC method. A statistical comparison using the F-ratio and Student's ttests did not reveal any difference between the official and the new methods. The $F$ test did not show any variance between the two methods while the t-test did not reveal any statistically significant difference in their recoveries. The two tests therefore showed no statistically significant differences between the precision and accuracy of the two methods and established the proposed method as a reliable alternative to the official method. However, the new method exhibited some greater advantages over the HPLC method.
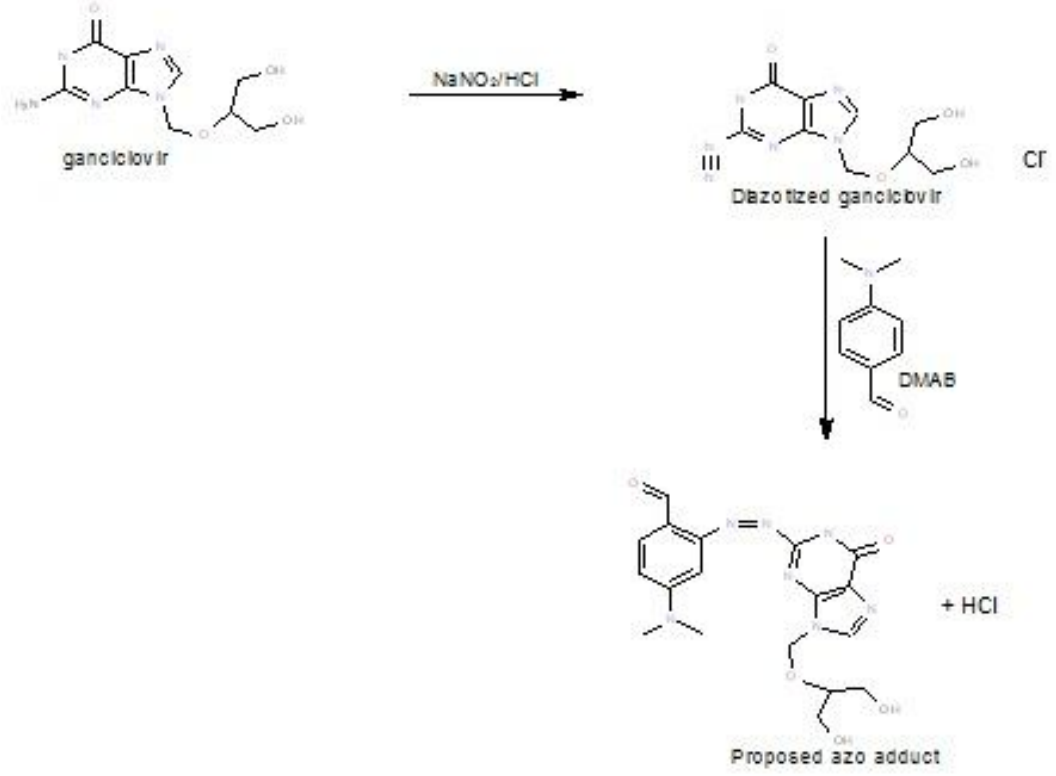

Figure 2: Proposed coupling reaction pattern between diazotized ganciclovir and DMAB 
Compared to the official HPLC assay, the new method is simple, inexpensive and faster because of the long retention of ganciclovir on HPLC columns. The performance of the new method also compared favorably with other UV visible methods with the added advantage of employing readily available, affordable and chemically stable reagents. The DMAB solution produced reproducible results for up to 7 days and 14 days when stored at room temperature and $4{ }^{\circ} \mathrm{C}$ respectively.

\section{CONCLUSION}

A new visible spectrophotometric method for the quantification of ganciclovir has been developed and validated. The method can serve as a reliable and affordable assay method for the routine analysis of ganciclovir in bulk and dosage forms.

\section{REFERENCES}

1. Perrottet N, Decosterd LA, Meylan P, Pascual M, Biollaz J, Buclin T. Valganciclovir in adult solid organ transplant recipients: pharmacokinetic and pharmacodynamic characteristics and clinical interpretation of plasma concentration measurements. Clin Pharmacokinet. 2009; 48: 399418.

2. Asberg A, Rollag $H$, Hartmann A. Valganciclovir for the prevention and treatment of CMV in solid organ transplant recipients. Expert Opin Pharmacother. 2010; 11: 1159-1166.

3. Matthews T, Boehme R. Antiviral activity and mechanism of action of ganciclovir. Rev Infect Dis. 1988; 10: S490-S494.

4. Martindale The Complete Drug Reference ed 36. London, Pharmaceutical Press, 2009.

5. Padulles A, Colom H, Armendariz Y, Cerezo G, Caldes A, Pou L, Torras J, Grinyo JM, Lloberas N. Determination of ganciclovir in human plasma by ultra performance liquid chromatography-UV detection. Clin Biochem. 2012; 45: 309-314.

6. Merodio M, Campanero MA, Mirshahi T, Mirshahi M, Irache JM. Development of a sensitive method for the determination of ganciclovir by reversed-phase highperformance liquid chromatography. J Chromatogr. 2000; 870: 159-167.

7. Boscha ME, Sánchezb A J, Rojasc FS, Ojedac CB. Ganciclovir: a review of its analytical determination. AJPS 2009; 4: 254-264.

8. Reddy CM, Reddy GV. Determination of ganciclovir in bulk and pharmaceutical dosage forms by UV spectromphotometric method. Int Res J Pharm. 2012; 3: 286-288.

9. Uslu B, Doğan B, Ozkan SA. Electrochemical studies of ganciclovir at glassy carbon electrodes and its direct determination in serum and pharmaceutics by square wave and differential pulse voltammetry. Anal chim acta 2005; 537: 307-313.

10. Sarsambi PS, Sonawane A, Faheem A. Development and validation of RP-HPLC method for the determination of ganciclovir in bulk drug and its formulations. Int J Pharm. Bio. Sci. 2010; 1: 1-7.

11. Ramesh PJ, Basavaiah K, Xavier CM, Prashanth KN, Raghu MS, Vinay KB. Titrimetric and Spectrophotometric Assay of Ganciclovir in Pharmaceuticals Using Cerium (IV) Sulphate as the Oxidimetric Agent. ISRN Anal Chem. 2012: 1-8.

12. Gouda AA, Amin AS. Utility of inorganic oxidants for the spectrophotometric determination of ganciclovir in dosage forms. Lat. Am. J. Pharm. 2011; 30: 334-341.

13. Gouda AA. Utility of certain sigma- and pi-acceptors for the spectrophotometric determination of ganciclovir in pharmaceutical formulations. Talanta 2009; 80: 151157.

14. Al-Neaimy UI, Al-Delymi AMS. Visible Spectrophotometric Determination of Ganciclovir in its Pharmaceutical Formulations using Quinalizarin Reagent. Jord J Chem. 2013; 8: 103-112.

15. Kumar TA, Gurupadayya BM, Reddy MBR. Selective and Validated Spectrophotometric Assay for Microgram Determination of Ganciclovir with 1-fluoro-2, 4dinitrobenzene and N-Bromosuccinimide Reagents. J Appl Chem Res. 2012; 20: 14-27.

16. Thomas OE, Adegoke OA. Development and validation of a new spectrophotometric method for the determination of acyclovir. J Pharmacy \& Bioresources 2012; 9: 75-84.

17. Adegoke OA. Analytical, biochemical and synthetic applications of para-dimethylaminobenzaldehyde. Int J Pharm Sci Rev Res. 2011; 11: 17-29.

18. Karnes HT, March C. Precision, accuracy and data acceptance criteria in biopharmaceutical analysis. Pharm. Res. 1993; 10: 1420-1426.

19. Rose J. Advanced Physico-Chemical Experiments. London: Pitman; 1964 p. 52.

20. ICH Guidelines Q2 (R1). Validation of Analytical Procedures: Text and Methodology. Date accessed 20 June 2013.

21. United States Pharmacopoeia 30/National Formulary 25. Rockville,Md., USA, 2007.

22. Adegoke OA, Umoh OE. A new approach to the spectrophotometric determination of metronidazole and tinidazole using p-dimethylaminobenzaldehyde. Acta Pharm. 2009; 59: 407-419. 